\title{
Large carabids enhance weed seed removal in organic fields and in large-scale, but not small-scale agriculture
}

\author{
Christina Fischer (D) - Friederike Riesch (D) Teja Tscharntke (D) \\ Péter Batáry (D)
}

Received: 18 November 2019/Accepted: 9 November 2020/Published online: 21 November 2020

(C) The Author(s) 2020

\begin{abstract}
Context Biological weed control by seed predators is an ecosystem service reducing weed population densities in agricultural landscapes. Drivers of seed predation are manifold and may change with spatial scales considered.

Objectives We aimed at identifying the functional identity of seed predators, food web interactions and feeding links between weed and wheat seeds, considering the causal relationships between local and landscape-scale patterns.
\end{abstract}

Electronic supplementary material The online version of this article (https://doi.org/10.1007/s10980-020-01157-8) contains supplementary material, which is available to authorized users.

\footnotetext{
C. Fischer $(\bowtie)$

Restoration Ecology, Department of Ecology and Ecosystem Management, Technische Universität München, Emil-Ramann-Str. 6, 85354 Freising, Germany e-mail: christina.fischer@tum.de

C. Fischer

Faunistics and Wildlife Conservation, Department of Agriculture, Ecotrophology, and Landscape Development, Anhalt University of Applied Sciences, Strenzfelder Allee 28, 06406 Bernburg, Germany

F. Riesch

Grassland Science, Department of Crop Sciences,

University of Goettingen, Von-Siebold-Str. 8,

37075 Göttingen, Germany
}

Methods We investigated direct and indirect effects of local management intensity in winter wheat fields (organic vs. conventional farming), local crop characteristics (wheat density and height), edge effects, landscape composition (measured as land-use diversity) and configuration (edge length) on carabid beetles of different body size (large vs. small carabids), and removal of weed and wheat seeds.

Results We showed the importance of indirect localand landscape-scale effects for weed seed removal via the activity density, but not assemblage composition, of large, but not small carabids, which was driven by few ubiquitous species. The activity density of large carabids increased with decreasing wheat density and increasing wheat height, which was highest in organic fields and in landscapes with low compositional and

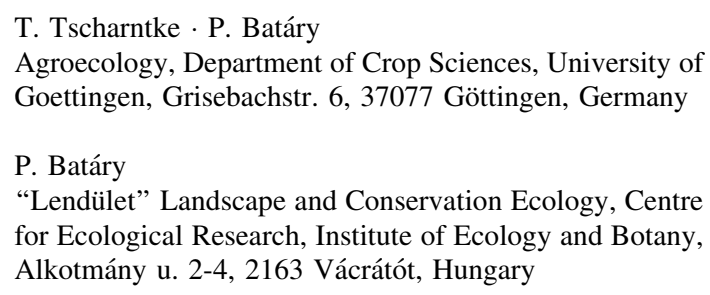


configurational heterogeneity. Further, the availability of nutrient-rich wheat seeds enhanced weed seed removal rates.

Conclusions We found highest weed seed removal via large carabids in organic fields in large-scale agricultural landscapes. Predator body size and species identity as well as the availability of additional food items need to be taken into account for better predicting the biological weed control potential and reducing the use of plant protection products.

Keywords Agricultural intensification - Weed control · Ecosystem services · Edge effect · Organic farming $\cdot$ Seed predation

\section{Introduction}

In times of land use changes and agricultural intensification, people are seeking for environmentally friendly farming methods including effective control of agricultural pests. Besides insect pests and pathogens, arable weeds that compete with the crops for resources can reduce agricultural yields significantly (Barzman et al. 2015). The most common agricultural practice to reduce weed densities is the use of herbicides. However, chemical plant protection can negatively affect farmland biodiversity, related ecosystem services and human health (Mahmood et al. 2016). An increasingly discussed ecosystem service, which can reduce weed population densities in agricultural fields, is the biological weed control by seed predators (reviewed in Petit et al. 2018; Sarabi 2019).

Studies of weed population dynamics showed that there is a significant effect of seed predators on plant recruitment (Crawley 2013), and that seed predation can contribute to weed suppression (Westerman et al. 2005). For example, Blubaugh and Kaplan (2016) found that seedling emergence of the lamb's quarters (Chenopodium album) was reduced in cover crops by $38 \%$ and its biomass was reduced by $81 \%$ due to seed predation. Small rodents and invertebrates, such as carabid beetles, are the most important ground-dwelling seed predators (reviewed in Sarabi 2019) and can altogether account for up to $60-70 \%$ of weed seed removal in cereal fields (Jonason et al. 2013). However, the contribution of invertebrates can be highly variable with weed seed predation ranging from 3 to 75\% (Trichard et al. 2013).

Even though many studies showed that weed seed predation by rodents often exceeds seed predation rates of ground-dwelling arthropods (Fischer et al. 2011; Tschumi et al. 2018), a recent study using molecular analysis of carabids' gastric content suggests that carabids can consume a very high amount of seeds (70\% plant food) throughout the entire vegetation period (Frei et al. 2019). Furthermore, ground-dwelling carabids primarily consume ripe seeds from the ground (Kotze et al. 2011; but see Sasakawa 2010), which is in contrast to small rodents, which are able to climb or cut down crop culms (Heroldová and Tkadlec 2011), and therefore have been also described as ecosystem disservice agents negatively affecting agricultural productivity (Fischer et al. 2018; Tschumi et al. 2018). Hence, the role of carabids, which can contribute to an effective weed control and thereby provide ecosystem services, but no disservices all over the growing season, should not be underrated (Kulkarni et al. 2015; Petit et al. 2018; Sarabi 2019).

In agricultural areas, multiple factors at different spatial scales influence carabid seed predation rates (Petit et al. 2018). At the local scale, vegetation cover (Meiss et al. 2010), increasing vegetation height (Pufal and Klein 2013; but see Kolb et al. 2007), increasing proximity to the center of the field (Saska et al. 2008), zero tillage regime (Menalled et al. 2007; but see Trichard et al. 2013), and occasionally organic farming may enhance seed predation rates by carabids (Trichard et al. 2013; but see Jonason et al. 2013; Rusch et al. 2016). Carabid seed predation is influenced by the size of the seed and the consumer species identity, with large carabid species preferring heavier seeds (Honek et al. 2007; Saska et al. 2019), as well as the energy content of seeds (Gaba et al. 2019). As carabids often show an opportunistic feeding behavior (Larochelle 1990), factors such as the availability of additional food items may also influence weed seed predation rates.

At the landscape scale, seed predation rates are enhanced by certain land cover types (annual crops: Jonason et al. 2013; permanent grassland and arable crops: Petit et al. 2017; the lower share of the target crop in general: Ricci et al. 2019; temporary pasture: Trichard et al. 2013). Local- and landscape-scale effects are shown to interact with each 
other, with seed removal being highest in organic fields in complex landscapes and lowest in conventional fields in simple landscapes (Fischer et al. 2011). There are several studies on the impacts of landscape composition, in terms of the amount of habitat/cover type or habitat diversity, on weed seed predation (Fischer et al. 2011; Jonason et al. 2013; Trichard et al. 2013; Rusch et al. 2016). However, the impacts of landscape configuration, that is the arrangement of spatial elements, have received much less attention, although it has been shown that increased configurational landscape heterogeneity can enhance weed seed removal by rodents (Fischer et al. 2018) as well as carabid functional diversity (Gallé et al. 2019) and community response (Duflot et al. 2017; Neumann et al. 2016).

Looking at the biotic drivers and food web interactions influencing weed seed predation rates, some studies reported positive relationships between carabid activity density or species richness and weed seed predation (Menalled et al. 2007; Jonason et al. 2013; Petit et al. 2017), whereas other studies did not find such relationships (Saska et al. 2008; Davis and Raghu 2010). Therefore, other features of carabid communities (cf. Saska et al. 2008), such as species composition (Rusch et al. 2016), size constrains (Honek et al. 2007; Saska et al. 2019), trophic level (Trichard et al. 2013; Petit et al. 2018), and species identity (Jowett et al. 2019) need to be taken into account. In addition, knowledge on food web interactions among carabids with different body size and trophic level, would contribute to a better understanding of the causal relationships between local- and landscape-scale effects on biological weed control in agricultural fields (cf. Davis and Raghu 2010; Petit et al. 2018).

Here, we investigated the direct and indirect effects of the activity densities of carabids of different body sizes and trophic levels, as well as their species identity and assemblage composition on the removal of weed and wheat seeds. We also considered localscale effects in terms of management intensity (organic vs. conventional farming) influencing local crop characteristics in terms of crop density and height, as well as edge effect and landscape-scale effects in terms of landscape composition (measured as land-use diversity) and configuration (edge length). We selected paired organic and conventional fields at both sides of the former inner German border. This way, we were able to directly compare the large-scale agricultural landscape in East Germany (mean field size 20 ha) with the small-scale agricultural landscape in West Germany (mean field size 3 ha; Batáry et al. 2017) to answer the following research questions:

(1) How do carabid species identity and assemblage composition influence the removal rates of weed and wheat seeds?

(2) Are there direct and indirect effects of local management intensity and landscape composition and configuration on the activity density of carabids of different body size, different trophic level and the removal rates of weed and wheat seeds?

\section{Materials and methods}

Study area and environmental variables

In order to study differences between regions with different landscape composition and configuration as well as management effects, we selected paired organic and conventional winter wheat fields in East (Thuringia, around the city of Mühlhausen, $51^{\circ} 13^{\prime} \mathrm{N}$, $10^{\circ} 27^{\prime} \mathrm{E}$ ) and West Germany (Lower Saxony, around the city of Göttingen, $51^{\circ} 32^{\prime} \mathrm{N}, 9^{\circ} 56^{\prime} \mathrm{E}$ ). In total, we selected nine field pairs $\times$ two regions $=36$ study sites. As the availability of organic farms was limited in East Germany, in this region, we selected in four villages two pairs of organic and conventional managed fields, respectively, and one further field pair near to another village. In West Germany, we had three villages with two field pairs and three villages with one field pair. In case we selected two field pairs per village, the same farmer managed both fields of the same management type. In order to study the effects of within-field position, we sampled at three different distances from the field edge: at the field edge (behind the first wheat row), at the field interior $(15 \mathrm{~m}$ from field edge) and at the field centre $(100 \pm 10 \mathrm{~m}$ from field edge in East and $54 \pm 5 \mathrm{~m}$ in West Germany due to different field sizes). In organically managed fields, no plant protection products and synthetic fertilizers were applied, whereas conventionally managed fields received 4-5 applications of plant protection products and ca. $180 \mathrm{~kg}$ nitrogen/ha per year. For details of the study site selection, management intensities, as well as 
a map of the study sites, see Batáry et al. (2017) and Fischer et al. (2018).

In order to study effects of local crop characteristics, in June 2014, we measured wheat height (mean \pm SE: $95 \pm 3 \mathrm{~cm}$, range: $70-147 \mathrm{~cm}$ ) and counted the number of wheat shoots at three $25 \times 25 \mathrm{~cm}$ plots, which were placed in the middle of each field, at each within field position with a distance of $10 \mathrm{~m}$ between each other. The number of wheat shoots per plot was scaled up to $1 \mathrm{~m}^{2}$ to obtain crop density $\left(554 \pm 30\right.$ shoots $/ \mathrm{m}^{2}$, range: $192-1083$ shoots $/ \mathrm{m}^{2}$ ). To match the spatial resolution of the other data, we calculated mean values of local crop characteristics per within-field position. Crop density was related to region and management, with higher crop density in East $\left(622 \pm 24\right.$ shoots $\left./ \mathrm{m}^{2}\right)$ compared to West Germany $\left(487 \pm 21\right.$ shoots $\left./ \mathrm{m}^{2}\right)$, and in conventionally $\left(619 \pm 23\right.$ shoots $\left./ \mathrm{m}^{2}\right)$ compared to organically managed fields (490 \pm 22 shoots/ $\mathrm{m}^{2}$ ). Wheat height was related to an interaction between region and management, with higher wheat shoots in organic fields in East Germany $(108 \pm 4 \mathrm{~cm})$ compared to conventional fields in East $(88 \pm 1 \mathrm{~cm})$ and West Germany $(87 \pm 2 \mathrm{~cm})$, which both exhibited lower wheat heights than organic fields in West Germany $(95 \pm 2 \mathrm{~cm})$.

In order to study landscape-scale effects among regions, we assessed the land-use diversity as a measure of crop landscape composition by calculating the Shannon diversity index (from the amount of cereal, oilseed rape, grassland, maize and other crops; $1.14 \pm 0.04$, range: $0.69-1.66$ ). As measures of landscape configuration we used the mean field size $(12.30 \pm 1.90$ ha, range: $1.58-44.08 \mathrm{ha})$ and edge length (16.77 $\pm 0.72 \mathrm{~km}$, range: $9.50-25.00 \mathrm{~km}$ ) (see Batáry et al. 2017). Landscape parameters were calculated for a $500 \mathrm{~m}$ radius around the field interior of focal fields using official digital topographical maps (ATKIS DTK 50) and the Geographical Information System (GIS) ArcGIS 10.2 (1999-2012 ESRI Inc.). The land-use diversity, mean field size and edge length were related to region, but not to management, with lower land-use diversity $(0.99 \pm 0.03)$ and edge length $(13.49 \pm 0.33 \mathrm{~km})$, but higher mean field size (21.05 \pm 1.35 ha) in East compared to West Germany (land-use diversity: $1.29 \pm 0.02$, edge length: $20.05 \pm 0.42 \mathrm{~km}$, mean field size: $3.55 \pm 0.22$ ). For details concerning local and landscape parameters related to region, management type and within-field position, see Fischer et al. (2018).

\section{Carabid sampling}

We assessed the activity density of carabid beetles twice for 4 days between the end of May and the beginning of June 2014 using two pitfall traps (diameter: $90 \mathrm{~mm}$, filled with $50 \%$ ethylene glycol and a drop of detergent to reduce surface tension) per within-field position, with a minimum distance of $10 \mathrm{~m}$ between each other ( $\mathrm{n}=432$ traps). Traps were buried flush with the soil surface and covered by a plastic roof $(160 \mathrm{~mm} \times 160 \mathrm{~mm})$ to protect them from overflowing during rainfall. We covered the opening of each trap by a $10 \mathrm{~mm}$ sized wire mesh to prevent small mammals from being trapped. Adult carabids were transferred to $70 \%$ ethanol and identified to species level using standard keys (Hurka 1996). Our recorded species were classified into two trophic groups: herbivorous or omnivorous species, feeding at least partly on seeds and plant material on the one hand, and, on the other hand, carnivorous species, feeding exclusively on animal material (classified after Larochelle 1990; Purtauf et al. 2005; Winqvist et al. 2014; Gallé et al. 2019). As carnivorous carabids do not directly affect seed removal, they were only considered when studying indirect effects on seed removal via bottom-up and top-down effects through herbivorous/omnivorous activity density using path analysis. Furthermore, we subclassified herbivorous/ omnivorous carabids according to their body size (classified after Homburg et al. 2013), as only large carabids are able to handle large seeds (Honek et al. 2007). Saska et al. (2019) found in a laboratory experiment that only Ophonus azureus with a body size of $7.5 \mathrm{~mm}$ fed on the seed species Galium aparine, which we used in our field study. Therefore, we grouped carabids with a body size $<7.5 \mathrm{~mm}$ into 'small carabids' and carabids with a body size $\geq 7.5 \mathrm{~mm}$ into 'large carabids'. We summed up the activity densities of each species for both pitfall traps per within-field position and sampling rounds to be in accordance with the temporal resolution of the local and landscape variables. 
Seed removal

We measured seed removal of G. aparine L. (Appels Wilde Samen $\mathrm{GmbH}$ ), which can be a harmful weed causing high yield losses in cereal fields (Gehring and Thyssen 2011), and which occured in almost all of our agricultural fields with a high cover in 2013, the year before our study (Batáry et al. 2017). We also measured the seed removal of wheat grains (Triticum aestivum L.) (Alnatura Produktions- und Handels $\mathrm{GmbH}$ ), which represent an additional food source for carabids that could modify the seed predation of the weed due to its higher energy content. Seed energy content differs between both plant species, with $G$. aparine seeds having a lipid content of $3.1 \%$ and a seed mass of $9 \mathrm{mg}$, and T. aestivum having a lipid content of $6.1 \%$ and a seed mass of $37 \mathrm{mg}$ (Royal Botanic Gardens Kew 2019). We exposed weed or wheat seeds to seed predators twice, between the end of May and the beginning of June 2014. Each round of the experiment comprised consecutive periods of weed and wheat seed exposure. To exclusively measure seed removal by invertebrates, we exposed one treatment excluding vertebrates and slugs but easily accessible to invertebrates. Therefore, we used cages with a mesh size of $12.7 \mathrm{~mm}$ framed by a $20 \mathrm{~mm}$ wide slug repellent copper tape ('invertebrate access'). Further, we used one treatment excluding all seed predators by using cages with a mesh size of $1 \mathrm{~mm}$ ('none'). Cages had a size of $210 \times 210 \times 60 \mathrm{~mm}(1 \times \mathrm{w} \times \mathrm{h})$ and were simultaneously placed next to each other at each within-field position (for details on the experimental set-up see Fischer et al. 2018). We offered 10 weed or wheat seeds per treatment in a Petri dish $(55 \mathrm{~mm}$ diameter, $14.2 \mathrm{~mm}$ height), which was buried flush with the soil surface and covered by a plastic roof to protect dishes from overflowing during rainfall. After four days at the first run and after two days at the second run, all remaining seeds were counted. Seed removal by invertebrates $\left(\mathrm{M}_{\mathrm{I}}\right)$ was calculated after Fox et al. (2013), with $M_{I}=\left(C_{N}-R_{I A}\right) / C_{N}$, where $R_{I A}$ is the number of seeds remaining in the 'invertebrate access' treatment, and $\mathrm{C}_{\mathrm{N}}$ is the number of seeds remaining in the 'none' treatment. In case $\mathrm{R}_{\mathrm{IA}}$ exceeded $\mathrm{C}_{\mathrm{N}}$ by more than 5:4, the data point was removed from the analysis (Fox et al. 2013), in all other cases $\mathrm{R}_{\mathrm{IA}}$ was set to $0 \%$ (Saska et al. 2008). From the overall $\mathrm{M}_{\mathrm{I}}$, we calculated the daily seed removal rate by invertebrates $\left(D_{S S R}\right.$ in
$\%)$ to account for the different exposure times during the first and second run, following Mittelbach and Gross (1984). For doing this, we assumed an exponential decline with $\operatorname{DSR}_{\mathrm{I}}=100 \times\left(1-\left(1-\mathrm{M}_{\mathrm{I}}\right)^{1 / \mathrm{t}}\right)$ [\%] and the exposure time $t$ in days. Mean $\mathrm{DSR}_{\mathrm{I}}$ of G. aparine and T. aestivum was calculated from both runs to be in accordance with the temporal resolution of the local and landscape variables (cf. Fischer et al. 2018).

\section{Statistical analysis}

In order to test for multicollinearity between numeric local and landscape variables, we performed correlation analysis (Spearman's rank correlation) and included only non-correlated variables $\left(\left|\mathrm{r}_{\mathrm{s}}\right|<0.7\right.$; Dormann et al. 2013) in further analyses. At the local scale, selected variables were crop density and wheat height, and at the landscape scale we selected edge length and land-use diversity (for details see Fischer et al. 2018). For all analyses, $R$ version 3.5.3 (R Core Team 2019) was used.

In order to test for the effects of the activity density of the most abundant herbivorous/omnivorous carabid species (independently of their body size) and our design variables, region (East vs. West), management (organic vs. conventional) and within-field position (edge, interior, centre), as well as the two-way interactions between activity densities and design variables on $\mathrm{DSR}_{\mathrm{I}}$ of $G$. aparine or $T$. aestivum, we used linear mixed-effects models (LME; Pinheiro and Bates 2000) with maximum likelihood implemented in the R package nlme (Pinheiro et al. 2016). Village $(\mathrm{n}=11)$ and field pair nested in village $(\mathrm{n}=18)$ were included as random effects accounting for the spatial autocorrelation of the study design to model the independence of errors (Pinheiro and Bates 2000). To achieve a normal error distribution and/or to avoid heteroscedasticity, the activity densities of the different species were $\log (\mathrm{x}+1)$ transformed and $\mathrm{DSR}_{\mathrm{I}}$ of $G$. aparine or $T$. aestivum were arcsine square root transformed. Models were simplified using an automatic backward stepwise model selection by Akaike's Information Criterion (AIC; Pinheiro and Bates 2000) using the 'stepAIC' function from the $\mathrm{R}$ package MASS (version 7.3-45; Venables and Ripley 2002). Fand p-values for all LMEs were derived from an ANOVA table and marginal and conditional $\mathrm{R}^{2}$-values of the models were extracted using the 
'r.squaredGLMM' function in the R package MuMIn (Barton 2019).

To study the causal relationships between the activity density of small and large herbivorous/ omnivorous carabids, as well as carnivorous carabids, related ecosystem functions ( $\mathrm{DSR}_{\mathrm{I}}$ of $G$. aparine or $T$. aestivum), local- (crop density and wheat height) and landscape-scale effects (edge length and land-use diversity) we used path analysis. Therefore, piecewise structural equation models (SEM) implemented in the $\mathrm{R}$ package piecewiseSEM (Lefcheck 2016) were applied. We hypothesised that both local- and landscape-scale effects affect the activity densities of small and large herbivorous/omnivorous and carnivorous carabids (reviewed in Kulkarni et al. 2015), as well as the intensity of $\mathrm{DSR}_{\mathrm{I}}$ of G. aparine and T. aestivum (reviewed in Sarabi 2019). We tested for bottom-up effects among carabids of different trophic levels, expecting herbivores/omnivores enhancing the activity densities of carnivores, as well as for top-down effects, showing the opposite relationship (Ripple et al. 2016). Further we expected that large carabids lead to lower activity density of small carabids due to top-down regulation of searching behaviour (Charalabidis et al. 2017). Lastly, we hypothezised that herbivores/omnivores affect seed removal rates (Brooks et al. 2012). The structure of the component models was similar to the LMEs described above, using the same random effect structure as well as the same parameter transformations. We applied a manual backward model selection based on AIC by removing variables with lowest significance $(p>0.05)$ from the global SEM, which includes all possible paths, until the minimal SEM with the lowest AIC was reached. Standardized path coefficients and related p-values, marginal and conditional $\mathrm{R}^{2}$-values for component models, as well as Fisher's $\mathrm{C}$ statistic were extracted (for path analysis details, see Online Resource 1). In the text and figures means and standard errors are given.

\section{Results}

In total, we trapped 8769 carabid beetles in the 36 winter wheat fields, belonging to 84 species (of which 73 species made up less than $1 \%$ of the total activity density; Online Resource 2). Mean carabid activity density was $244 \pm 37$ individuals/field $(n=36)$. We identified 35 herbivorous/omnivores species (3602 individuals, $100 \pm 25$ individuals/field) and 49 carnivorous species (5167 individuals, $144 \pm 19$ individuals/field). The most abundant herbivorous/ omnivorous species were Poecilus cupreus (1643 individuals $=45.61 \%$ of the total carabid activity density), followed by Pseudoophonus rufipes (1193 individuals $=33.12 \%$ ), Harpalus affinis (224 individuals $=6.22 \%$ ), Brachinus crepitans (128 individuals $=3.55 \%), \quad$ Bembidion obtusum $\quad(125$ individuals $=3.47 \%$ ), and Amara ovata (43 individuals $=1.19 \%$ ). Looking at the size of herbivorous/ omnivores carabids, we identified 11 small species (258 individuals, $7 \pm 1$ individuals/field; mean body size: $6.23 \pm 0.40 \mathrm{~mm}$, range: $2.5-7 \mathrm{~mm}$ ) and 24 large species (3344 individuals, $93 \pm 25$ individuals/field; mean body size: $9.92 \pm 0.47 \mathrm{~mm}$, range: $7.5-15 \mathrm{~mm}$; Online Resource 2).

At the local scale, assemblage composition of small carabids was not influenced by any of the tested parameters, whereas assemblage composition of large carabids was influenced by within-field position and wheat height. At the landscape scale, edge length, land-use diversity and region influenced assemblage composition of large, but not small carabids (assessed via non-metric multidimensional scaling using the $\mathrm{R}$ package vegan, Oksanen et al. 2019; for details see Online Resource 3). Daily seed removal by invertebrates per within-field position and field was almost equal for G. aparine $(28.86 \pm 2.92 \% ; \mathrm{n}=108)$ and $T$. aestivum $(28.88 \pm 3.06 \%)$. Assemblage composition of small and large carabids did not influence DSR $_{\mathrm{I}}$ of weed and wheat seeds (see Online Resource 3).

Looking at the most abundant herbivorous/omnivorous carabid species, our results show that only the activity density of $P$. rufipes was positively related to $\mathrm{DSR}_{\mathrm{I}}$ of $G$. aparine. Furthermore, increasing activity density of $P$. cupreus increased $\mathrm{DSR}_{\mathrm{I}}$ of $G$. aparine in organically managed fields, but decreased it in conventionally managed fields (Table 1 ). There was no relationship between $\mathrm{DSR}_{\mathrm{I}}$ of $T$. aestivum and any of the tested carabids species (Table 1). The predictive capacity of our single species models was very low and did not explain weed and wheat seed removal sufficiently (as reflected by very low marginal and conditional $\mathrm{R}^{2}$ values $\leq 0.10$; Table 1 ).

Results of the path analysis studying bottom-up effects (Fisher's $\mathrm{C}_{26}=17.54, \quad \mathrm{p}=0.892, \quad \mathrm{AIC}=$ 91.54) had a slightly higher predictive capacity than 
Table 1 Effects of the activity density of the most abundant herbivorous (h) and omnivorous (o) carabids, landscape (region = R) and local scale (management intensity $=\mathrm{M}$ ), as well as within-field position (P) with two-way interactions among carabid activity density (AD) and the design variables on daily weed and wheat seed removal by invertebrates

\begin{tabular}{|c|c|c|c|c|c|c|c|c|c|c|c|c|}
\hline & \multicolumn{2}{|c|}{$\begin{array}{l}\text { Amara } \\
\text { ovata }\end{array}$} & \multicolumn{2}{|c|}{$\begin{array}{l}\text { Bembidion } \\
\text { obtusum }\end{array}$} & \multicolumn{2}{|c|}{$\begin{array}{l}\text { Brachinus } \\
\text { crepitans }\end{array}$} & \multicolumn{2}{|c|}{$\begin{array}{l}\text { Harpalus } \\
\text { affinis }\end{array}$} & $\begin{array}{l}\text { Poecilus } \\
\text { cupreus }\end{array}$ & \multicolumn{3}{|c|}{$\begin{array}{l}\text { Pseudoophonus } \\
\text { rufipes }\end{array}$} \\
\hline $\begin{array}{l}\text { Feeding } \\
\text { preference }\end{array}$ & $\mathrm{h}$ & & o & & o & & o & & o & o & & \\
\hline \multirow[t]{2}{*}{ Body size (mm } & 8.5 & & 2.5 & & 8 & & 10 & & 11 & & & \\
\hline & $\begin{array}{l}R_{m}^{2} \\
0.04\end{array}$ & $\begin{array}{l}R_{c}^{2} \\
0.10\end{array}$ & $\begin{array}{l}R_{m}^{2} \\
0.00\end{array}$ & $\begin{array}{l}R_{c}^{2} \\
0.03\end{array}$ & $\begin{array}{l}R_{m}^{2} \\
0.00\end{array}$ & $\begin{array}{l}R_{c}^{2} \\
0.03\end{array}$ & $\begin{array}{l}R_{m}^{2} \\
0.00\end{array}$ & $\begin{array}{l}R_{c}^{2} \\
0.03\end{array}$ & $\begin{array}{l}R_{m}^{2} \\
0.07\end{array}$ & $\begin{array}{l}R_{c}^{2} \\
0.07\end{array}$ & $\begin{array}{l}R_{m}^{2} \\
0.00\end{array}$ & $\begin{array}{l}R_{c}^{2} \\
0.03\end{array}$ \\
\hline $\begin{array}{l}\text { Weed seed } \\
\text { removal }\end{array}$ & $\mathrm{F}$ & $\mathrm{p}$ & $\mathrm{F}$ & $\mathrm{p}$ & $\mathrm{F}$ & $\mathrm{p}$ & $\mathrm{F}$ & $\mathrm{p}$ & $\mathrm{F}$ & $\mathrm{p}$ & $\mathrm{F}$ & $\mathrm{p}$ \\
\hline Intercept & 107.73 & $<0.001$ & 127.74 & $<0.001$ & 127.74 & $<0.001$ & 127.74 & $<0.001$ & 168.99 & $<0.001$ & 175.88 & $<0.001$ \\
\hline $\mathrm{R}$ & - & - & - & - & - & - & - & - & - & - & - & - \\
\hline M & 1.47 & 0.229 & - & - & - & - & - & - & 1.43 & 0.235 & - & - \\
\hline $\mathrm{P}$ & - & - & - & - & - & - & - & - & - & - & - & - \\
\hline $\mathrm{AD}$ & 0.98 & 0.325 & - & - & - & - & - & - & 1.11 & 0.295 & 9.28 & 0.003 \\
\hline $\mathrm{R} \times \mathrm{AD}$ & - & - & - & - & - & - & - & - & - & - & - & - \\
\hline $\mathrm{M} \times \mathrm{AD}$ & 2.21 & 0.141 & - & - & - & - & - & - & 4.42 & 0.039 & - & - \\
\hline $\mathrm{P} \times \mathrm{AD}$ & - & - & - & - & - & - & - & - & - & - & - & - \\
\hline $\begin{array}{l}\text { Wheat seed } \\
\text { removal }\end{array}$ & $\begin{array}{l}R_{m}^{2} \\
0.03\end{array}$ & $\begin{array}{l}R_{c}^{2} \\
0.03\end{array}$ & $\begin{array}{l}R_{m}^{2} \\
0.00\end{array}$ & $\begin{array}{l}R_{c}^{2} \\
0.00\end{array}$ & $\begin{array}{l}R_{m}^{2} \\
0.00\end{array}$ & $\begin{array}{l}R_{c}^{2} \\
0.00\end{array}$ & $\begin{array}{l}R_{m}^{2} \\
0.00\end{array}$ & $\begin{array}{l}R_{c}^{2} \\
0.00\end{array}$ & $\begin{array}{l}R_{m}^{2} \\
0.00\end{array}$ & $\begin{array}{l}R_{c}^{2} \\
0.00\end{array}$ & $\begin{array}{l}R_{m}^{2} \\
0.00\end{array}$ & $\begin{array}{l}R_{c}^{2} \\
0.00\end{array}$ \\
\hline Intercept & 127.93 & $<0.001$ & 127.94 & $<0.001$ & 127.74 & $<0.001$ & 127.94 & $<0.001$ & 127.94 & $<0.001$ & 127.94 & $<0.001$ \\
\hline $\mathrm{R}$ & - & - & - & - & - & - & - & - & - & - & - & - \\
\hline M & 0.23 & 0.630 & - & - & - & - & - & - & - & - & - & - \\
\hline $\mathrm{P}$ & - & - & - & - & - & - & - & - & - & - & - & - \\
\hline $\mathrm{AD}$ & 0.17 & 0.684 & - & - & - & - & - & - & - & - & - & - \\
\hline $\mathrm{R} \times \mathrm{AD}$ & - & - & - & - & - & - & - & - & - & - & - & - \\
\hline $\mathrm{M} \times \mathrm{AD}$ & 2.59 & 0.111 & - & - & - & - & - & - & - & - & - & - \\
\hline $\mathrm{P} \times \mathrm{AD}$ & - & - & - & - & - & - & - & - & - & - & - & - \\
\hline
\end{tabular}

Results of minimal adequate linear mixed-effects models showing marginal $\left(R_{m}^{2}\right)$ and conditional $\left(R_{c}^{2}\right) \mathrm{R}^{2}$-values for the respective models, and F- and p-values for the activity density of the respective species from an ANOVA table are given

path analysis studying top-down effects (Fisher's $\mathrm{C}_{20}=13.31, \mathrm{p}=0.864 ;$ AIC $=93.31$; for details see Online Resource 1). Those bottom-up effects models showed direct local- and landscape-scale effects on the activity density of carabids, but only indirect effects on $\mathrm{DSR}_{\mathrm{I}}$ of $G$. aparine. There was no direct or indirect effect of local and landscape-scale parameters on $\mathrm{DSR}_{\mathrm{I}}$ of $T$. aestivum. Therewith path analysis largely corresponded with the results of individual models using our design variables (Online Resource 2). The activity density of small herbivorous/omnivorous carabids marginally decreased with increasing landuse diversity, without any effect of local-scale parameters. The activity density of large herbivorous/ omnivorous carabids decreased with increasing wheat density and marginally increased with increasing wheat height. Land-use diversity and edge length had no effects on the activity density of large carabids, but regarding our design variables, the activity density of large carabids was higher in the East compared to the West (Online Resource 2). The activity density of carnivorous carabids decreased with increasing land- 


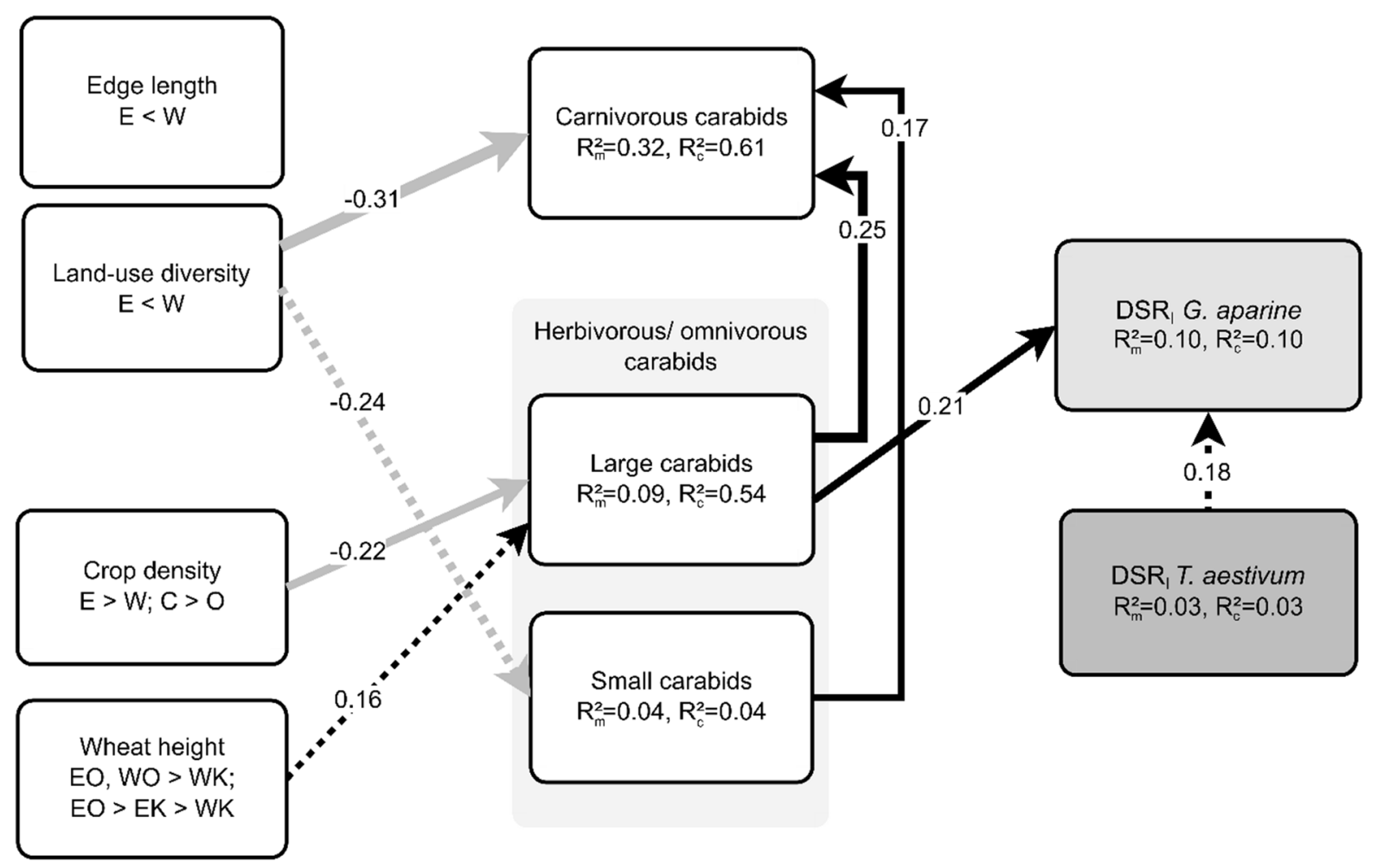

Fig. 1 Causal relationships among landscape variables (edge length, land-use diversity), local characteristics of the crop (crop density, wheat height), and activity density of small and large herbivorous/omnivorous carabids and bottom-up effects on carnivorous carabids, as well as daily weed and wheat seed removal derived from path analysis. Differences among local and landscape variables between East (E) and West (W) Germany, and organically (O) and conventionally (C) managed fields are shown below each parameter. Arrows represent unidirectional relationships among variables. Black arrows

use diversity, whereas local-scale parameters had no direct effects on carnivores' activity density. Bottomup effects showed that both small and large herbivores/omnivores increased carnivores' activity density (Fig. 1). Daily weed seed removal by invertebrates was directly positively affected by the activity density of large, but not small carabids, whereas $\mathrm{DSR}_{\mathrm{I}}$ of $T$. aestivum was not affected by carabid activity density. However, increasing $\operatorname{DSR}_{\mathrm{I}}$ of T. aestivum increased $\mathrm{DSR}_{\mathrm{I}}$ of G. aparine (Fig. 1).

\section{Discussion}

Our study shows that large carabids, which were the main drivers of weed seed removal, were positively represent positive relationships and grey arrows represent negative relationships. Solid lines indicate significant paths $(p<0.05)$ and dashed lines indicate marginally significant paths $(p<0.10)$. Thickness of lines has been scaled to the magnitude of the standardized regression coefficient (given above the arrows). Marginal $\left(R_{m}^{2}\right)$ and conditional $\left(R_{c}^{2}\right) \mathrm{R}^{2}$ values from component models are given for each response variable (for details see Online Resource 1)

affected by organic farming, determined by low wheat density and high wheat height and large-scale agriculture. There were no direct effects of local and landscape-scale parameters on weed seed removal rates. In addition to the effect of single ubiquitous large carabid species, weed seed removal was positively affected by the removal of wheat seeds. There were no direct effects of small carabids or indirect effects of carnivorous carabids, as well as carabid assemblage composition on weed or wheat seed removal.

Local- and landscape-scale effects on carabids

Our study shows that mainly local management effects, but also landscape-scale effects are the driving 
factors explaining the community and the occurrence of large, but not small carabids (Trichard et al. 2013; but see Winqvist et al. 2014). The activity density of large carabids was higher in organic compared to conventional fields, and in the East compared to the West. This was positively related to the wheat height (shown by our SEM), which was also highest in organic fields in the East and negatively related to crop density, which was lower in organic compared to conventional fields. Rouabah et al. (2015) showed that medium- sized carabids (mainly P. cupreus, which was also the most abundant species here) are associated with high vegetation. Increasing vegetation height increases vegetation structural complexity and therewith provides essential refuges for carabids $(\mathrm{Ng}$ et al. 2018), reducing the competition with other invertebrates such as spiders (Birkhofer et al. 2011). Furthermore, lower crop density in organic fields may have decreased vegetation heterogeneity and therewith increased habitat permeability for large carabids (Rouabah et al. 2015).

At the landscape scale, the activity density of small herbivores/omnivores and carnivorous carabids decreased with increasing land-use diversity. Additionally, the activity density of large herbivores/ omnivores carabids was higher in the East compared to the West. This negative effect of small-scale agriculture on the activity density of carabids (cf. Jonason et al. 2013; Winqvist et al. 2014; but see Purtauf et al. 2005; Trichard et al. 2013) can be explained by the most abundant species in our study. Species such as $P$. cupreus, $P$. rufipes, $H$. affinis, $B$. crepitans, and $A$. ovata are marcopterous habitat generalists or open-habitat species (classification after Fischer et al. 2013), and are well adapted to the largescale agriculture (cf. Gallé et al. 2019). Further factors such as negative edge effects through predator avoidance (cf. Anjum-Zubair et al. 2010), or the use of field centers as overwintering habitats by e.g. P. melanarius (Holland et al. 2007), which was one of the most abundant carnivorous species, could lead to negative effects of increasing land-use diversity on the activity density of carabids. However, the generally weak response of carabids to local management intensity and landscape-scale effects, as well as the lack of response to separate landscape compositional and configurational effects may have been blurred by other factors. For example, the amount of semi-natural habitats in the landscape can increase the diversity of granivorous carabids (Purtauf et al. 2005; Trichard et al. 2013) and additional ecological traits, such as carabids' mobility (Gallé et al. 2019) or species identity (Purtauf et al. 2005), may be better predictors to study local- and landscape-scale effects on carabids.

Linking carabid communities and food web interactions to weed seed removal

Our study failed to detect direct local- and landscapescale effects or edge effects, as well as effects of carabid assemblage composition on weed seed removal. Furthermore, the removal of wheat seeds was also not affected by any of these variables. At a local scale, other studies also failed to detect effects of organic farming on seed removal by carabids (Jonason et al. 2013; Rusch et al. 2016; but see Trichard et al. 2013). As organic farming enhances within-field plant species richness and therewith the seed availability (Roschewitz et al. 2005), the huge variety of alternative food may have led to a reduced consumption of our tested seed species. Together with lower predator activity density in conventional fields in terms of large carabids, this may result in no detectable differences in seed predation rates depending on local management intensity.

Surprisingly, there was a lack of direct landscapescale and edge effects on seed removal rates, which cannot be explained by this mechanism. Due to lower activity densities of large carabids in small-scale agriculture (West), seed removal rates should be highest in large-scale agriculture (cf. Jonason et al. 2013; but see Trichard et al. 2013), where seed/plant availability is also reduced (Roschewitz et al. 2005). This coherence underlines the importance of indirect local and landscape effects on weed seed removal via the activity density of carabids. Here, we could show that with increasing activity density of large, but not small carabids, seed removal rates of $G$. aparine increased (Honek et al. 2007; Menalled et al. 2007; Jonason et al. 2013). Thereby weed or wheat seed removal rates were not driven by the assemblage composition of carabids of different size, but rather by few very abundant species (cf. Rusch et al. 2016), such as $P$. rufipes, whose diet is known to consist of more than $90 \%$ plant material (Frei et al. 2019). Cooccurring with other key seed predators from the taxa Harpalus and Poecilus, these carabids strongly facilitate seed predation (Carbonne et al. 2020). This 
positive relationship between weed seed removal and the activity density of (the most abundant) large carabids is of particular importance in terms of biological weed control of large weed seeds (Honek et al. 2007). Even though there are taxonomic constrains determining seed predation rates of carabids, large-seeded plant species such as G. aparine can be destroyed by carabids damaging the seed coat when feeding (Honek et al. 2007; Saska et al. 2019). Further, as smaller seeds of economically important weed species (Gehring and Thyssen 2011), such as Tripleurospermum inodorum are consumed by a much wider variety of carabids common to arable land (Saska et al. 2019), it is likely that our study strongly underestimates the seed loss by invertebrates. Although the daily weed seed removal of $G$. aparine was much higher than in other studies (Alignier et al. 2008: $19 \%$ in 7 days; Fischer et al. 2011: 18\% in 2 days), 28\% seed loss by invertebrates does not fully reach the critical level of $25-50 \%$, which was shown to successfully supress weed populations (reviewed in Petit et al. 2018). Therefore, the overall annual seed loss by invertebrates and vertebrates, as well as other mortality factors, such as deep burial or decay, need to be considered to properly predict weed population dynamics (Nathan and Muller-Landau 2000) and within-field weed suppression (Kulkarni et al. 2015).

Looking at food web interactions, we detected a strong bottom-up effect along the food chain. As carnivorous carabids often prey upon larvae and pupae of other beetles and occasionally show cannibalism (Larochelle 1990), it can be well explained that herbivorous/omnivorous carabids positively influenced the activity density of carnivorous species. However, top-down effects via carnivorous carabids supressing herbivorous and omnivorous carabids (Ripple et al. 2016) and therewith indirectly affecting weed or wheat seed removal through a combination of parasitism and predation (Petit et al. 2017), were of little importance. Further, we also could not detect any top-down regulation of the searching behaviour of small carabids by large species (Charalabidis et al. 2017). Therefore, other factors determining carabids' seed predation rates, such as seed characteristics in terms of seed size and nutrient content, might be more important than food web interactions (Honek et al. 2007; Gaba et al. 2019). Here we show a mutual relationship between weed and wheat seed removal. The higher lipid content and the higher seed mass of fallen wheat grains can lead to higher weed seed removal rates especially through large carabids, which are able to handle large seeds (Honek et al. 2007; Saska et al. 2019). Even though we could not find any direct effect of carabids on wheat seed removal, a high availability of nutrient-rich alternative food, which is important for the carabids life cycle in terms of fecundity, growth and development (reviewed in Kulkarni et al. 2015), may enhance carabids' activity densities and therewith positively affect biological weed control.

\section{Conclusion}

Understanding the drivers of weed seed removal in agricultural fields and the related biological control potential requires the identification of the causal relationships between local- and landscape-scale effects, the functional identity of carabids as seed predators, their food web interactions and feeding links between weed seeds and additional food items (Petit et al. 2018). Here we show the importance of indirect local- and landscape-scale effects, as well as the availability of nutrient-rich additional food items (wheat seeds) on weed seed removal via the enhanced activity density of carabids, which was mainly driven by few ubiquitous species. Large, but not small, herbivorous/omnivorous carabids, were the driving predator group, being most abundant in organic fields free of pesticide use, with a low crop density and high wheat height in large-scale agricultural areas. However, even if weed seed removal rates are increased in large-scale landscapes, the loss of landscape-scale heterogeneity may threaten farmland biodiversity in general (Sirami et al. 2019), and is in conflict with other yield-enhancing ecosystem services, such as pollination and pest control (Martin et al. 2019).

Acknowledgements The data for this article were assessed in the frame of the project "Biodiversity and associated ecosystem services in small- vs. large-scale agriculture" (Deutsche Forschungsgemeinschaft BA 4438/1-1). PB was supported by the Hungarian National Research, Development and Innovation Office (NKFIH KKP 133839). We thank Péter Császár for identifying the carabid beetles, Kornélia Kurucz, Christoph Gayer, Julia Sevillano Pires, and Silvia Fusaro for help with the field work, the farmers who allowed us to work in their fields, and two anonymous reviewers for their valuable comments. 
Open Access This article is licensed under a Creative Commons Attribution 4.0 International License, which permits use, sharing, adaptation, distribution and reproduction in any medium or format, as long as you give appropriate credit to the original author(s) and the source, provide a link to the Creative Commons licence, and indicate if changes were made. The images or other third party material in this article are included in the article's Creative Commons licence, unless indicated otherwise in a credit line to the material. If material is not included in the article's Creative Commons licence and your intended use is not permitted by statutory regulation or exceeds the permitted use, you will need to obtain permission directly from the copyright holder. To view a copy of this licence, visit http://creativecommons.org/licenses/by/4.0/.

Funding Open Access funding enabled and organized by Projekt DEAL.

\section{References}

Alignier A, Meiss H, Petit S, Reboud X (2008) Variation of postdispersal weed seed predation according to weed species, space and time. J Plant Dis Prot 21:221-226

Anjum-Zubair M, Schmidt-Entling MH, Querner P, Frank T (2010) Influence of within-field position and adjoining habitat on carabid beetle assemblages in winter wheat. Agric For Entomol 12:301-306

Barton K (2019) MuMIn: Multi-Model Inference. R package version 1.43 .6

Barzman M et al (2015) Eight principles of integrated pest management. Agron Sustain Dev 35:1199-1215

Batáry P et al (2017) The former Iron Curtain still drives biodiversity-profit trade-offs in German agriculture. Nat Ecol Evol 1:1279-1284

Birkhofer K, Wolters V, Diekötter T (2011) Density-dependent and -independent effects on the joint use of space by predators and prey in terrestrial arthropod food-webs. Oikos 120:1705-1711

Blubaugh CK, Kaplan I (2016) Invertebrate seed predators reduce weed emergence following seed rain. Weed Sci 64:80-86

Brooks DR, Storkey J, Clark SJ, Firbank LG, Petit S, Woiwod IP (2012) Trophic links between functional groups of arable plants and beetles are stable at a national scale. J Anim Ecol 81:4-13

Carbonne B, Bohan DA, Petit S (2020) Key carabid species drive spring weed seed predation of Viola arvensis. Biol Control 141:104148

Charalabidis A, Dechaume-Moncharmont FX, Petit S, Bohan DA (2017) Risk of predation makes foragers less choosy about their food. PLoS ONE 12:1-8

Crawley MJ (2013) Seed predators and plant population dynamics. In: Gallagher RS (ed) Seeds: the ecology of regeneration in plant communities, 3rd edn. CAB International, Wallingford, pp 94-111

Davis AS, Raghu S (2010) Weighing abiotic and biotic influences on weed seed predation. Weed Res 50:402-412
Dormann CF et al (2013) Collinearity: a review of methods to deal with it and a simulation study evaluating their performance. Ecography 36:27-46

Duflot R, Ernoult A, Aviron S, Fahrig L, Burel F (2017) Relative effects of landscape composition and configuration on multi-habitat gamma diversity in agricultural landscapes. Agric Ecosyst Environ 241:62-69

Fischer C, Thies C, Tscharntke T (2011) Mixed effects of landscape complexity and farming practice on weed seed removal. Perspect Plant Ecol Evol Syst 13:297-303

Fischer C, Schlinkert H, Ludwig M, Holzschuh A, Gallé R, Tscharntke T, Batáry P (2013) The impact of hedge-forest connectivity and microhabitat conditions on spider and carabid beetle assemblages in agricultural landscapes. J Insect Conserv 17:1027-1038

Fischer C, Gayer C, Kurucz K, Riesch F, Tscharntke T, Batáry P (2018) Ecosystem services and disservices provided by small rodents in arable fields: effects of local and landscape management. J Appl Ecol 55:548-558

Fox AF, Reberg-Horton SC, Orr DB, Moorman CE, Frank SD (2013) Crop and field border effects on weed seed predation in the southeastern US coastal plain. Agric Ecosyst Environ 177:58-62

Frei B, Guenay Y, Bohan DA, Traugott M, Wallinger C (2019) Molecular analysis indicates high levels of carabid weed seed consumption in cereal fields across Central Europe. J Pest Sci 92:935-942

Gaba S, Deroulers P, Bretagnolle F, Bretagnolle V (2019) Lipid content drives weed seed consumption by ground beetles (Coleopterea, Carabidae) within the smallest seeds. Weed Res 59:170-179

Gallé R, Happe AK, Baillod AB, Tscharntke T, Batáry P (2019) Landscape configuration, organic management, and within-field position drive functional diversity of spiders and carabids. J Appl Ecol 56:63-72

Gehring K, Thyssen S (2011) Integrierter Pflanzenschutz-Leitunkräuter in Getreide. Freising.

Heroldová M, Tkadlec E (2011) Harvesting behaviour of three central European rodents. Identifying the rodent pest in cereals. Crop Prot 30:82-84

Holland JM, Thomas CFG, Birkett T, Southway S (2007) Spatio-temporal distribution and emergence of beetles in arable fields in relation to soil moisture. Bull Entomol Res 97:89-100

Homburg K, Homburg N, Schäfer F, Schuldt A, Assmann T (2013) Carabids.org - a dynamic online database of ground beetle species traits (Coleoptera, Carabidae). Insect Conserv Divers 7:195-205

Honek A, Martinkova Z, Saska P, Pekar S (2007) Size and taxonomic constraints determine the seed preferences of Carabidae (Coleoptera). Basic Appl Ecol 8:343-353

Hurka K (1996) Carabidae of the Czech and Slovak republics. Vit Kabourek, Zlín, Czech Republic, Ing

Jonason D, Smith HG, Bengtsson J, Birkhofer K (2013) Landscape simplification promotes weed seed predation by carabid beetles (Coleoptera: Carabidae). Landsc Ecol 28:487-494

Jowett K, Milne AE, Metcalfe H, Hassall KL, Potts SG, Senapathi D, Storkey J (2019) Species matter when considering landscape effects on carabid distributions. Agric Ecosyst Environ 285:106631 
Kolb A, Leimu R, Ehrlen J (2007) Environmental context influences the outcome of a plant-seed predator interaction. Oikos 116:864-872

Kotze DJ et al (2011) Forty years of carabid beetle research in Europe - from taxonomy, biology, ecology and population studies to bioindication, habitat assessment and conservation. Zookeys. 25:55-148

Kulkarni SS, Dosdall LM, Willenborg CJ (2015) The role of ground beetles (Coleoptera: Carabidae) in weed seed consumption: a review. Weed Sci 63:355-376

Larochelle A (1990) The Food of Carabid Beetles (Coleoptera: Carabidae, including Cicindelinae) vol Supplément 5. Fabreries Association des Entomologistes Amateurs du Québec, Québec

Lefcheck JS (2016) PiecewiseSEM: Piecewise structural equation modelling in $\mathrm{R}$ for ecology, evolution, and systematics. Methods Ecol Evol 7:573-579

Mahmood I, Imadi SR, Shazadi K, Gul A, Hakeem KR (2016) Effects of Pesticides on Environment. In: Hakeem KR, Akhtar MS, Abdullah SNA (eds) Plant, Soil and Microbes, vol 1. Implications in Crop Science. Springer International Publishing, Cham, pp 253-269

Martin EA et al (2019) The interplay of landscape composition and configuration: new pathways to manage functional biodiversity and agroecosystem services across Europe. Ecol Lett 22:1083-1094

Meiss H, Le Lagadec L, Munier-Jolain N, Waldhardt R, Petit S (2010) Weed seed predation increases with vegetation cover in perennial forage crops. Agric Ecosyst Environ 138:10-16

Menalled FD, Smith RG, Dauer JT, Fox TB (2007) Impact of agricultural management on carabid communities and weed seed predation. Agric Ecosyst Environ 118:49-54

Mittelbach GG, Gross KL (1984) Experimental studies of seed predation in old-fields. Oecologia 65:7-13

Nathan R, Muller-Landau HC (2000) Spatial patterns of seed dispersal, their determinants and consequences for recruitment. Trends Ecol Evol 15:278-285

Neumann JL, Griffiths GH, Hoodless A, Holloway GJ (2016) The compositional and configurational heterogeneity of matrix habitats shape woodland carabid communities in wooded-agricultural landscapes. Landsc Ecol 31:301-315

Ng K, McIntyre S, Macfadyen S, Barton PS, Driscoll DA, Lindenmayer DB (2018) Dynamic effects of ground-layer plant communities on beetles in a fragmented farming landscape. Biodivers Conserv 27:2131-2153

Oksanen J et al. (2019) vegan: Community Ecology Package, R package version $2.5-4$

Petit S, Trichard A, Biju-Duval L, McLaughlin OB, Bohan DA (2017) Interactions between conservation agricultural practice and landscape composition promote weed seed predation by invertebrates. Agric Ecosyst Environ 240:45-53

Petit S, Cordeau S, Chauvel B, Bohan D, Guillemin JP, Steinberg C (2018) Biodiversity-based options for arable weed management. A review. Agron Sustain Dev 38:48

Pinheiro JC, Bates DM (2000) Mixed-Effects Models in S and S-PLUS. Springer, New York

Pinheiro J, Bates D, DebRoy S, Sarkar D, R Core Team (2016) nlme: Linear and Nonlinear Mixed Effects Models. R package version 3.1-128.

Pufal G, Klein AM (2013) Post-dispersal seed predation of three grassland species in a plant diversity experiment. J Plant Ecol 6:468-479
Purtauf T, Dauber J, Wolters V (2005) The response of carabids to landscape simplification differs between trophic groups. Oecologia 142:458-464

R Core Team (2019) R: a language and environment for statistical computing. R Foundation for Statistical Computing, Vienna

Ricci B et al (2019) Local pesticide use intensity conditions landscape effects on biological pest control. Pro Roy Soc B 286:1-5

Ripple WJ et al (2016) What is a trophic cascade? Trends Ecol Evol 31:842-849

Roschewitz I, Gabriel D, Tscharntke T, Thies C (2005) The effects of landscape complexity on arable weed species diversity in organic and conventional farming. J Appl Ecol 42:873-882

Rouabah A, Villerd J, Amiaud B, Plantureux S, Lasserre-Joulin F (2015) Response of carabid beetles diversity and size distribution to the vegetation structure within differently managed field margins. Agric Ecosyst Environ 200:21-32

Royal Botanic Gardens Kew (2019) Seed Information Database (SID). Version 7.1

Rusch A, Binet D, Delbac L, Thiery D (2016) Local and landscape effects of agricultural intensification on carabid community structure and weed seed predation in a perennial cropping system. Landsc Ecol 31:2163-2174

Sarabi V (2019) Factors that influence the level of weed seed predation: a review. Weed Biol Manag 19:61-74

Sasakawa K (2010) Field observations of climbing behavior and seed predation by adult ground beetles (Coleoptera: Carabidae) in a lowland area of the temperate zone. Environ Entomol 39:1554-1560

Saska P, van der Werf W, de Vries E, Westerman PR (2008) Spatial and temporal patterns of carabid activity-density in cereals do not explain levels of predation on weed seeds. Bull Entomol Res 98:169-181

Saska P, Honek A, Martinková Z (2019) Preferences of carabid beetles (Coleoptera: Carabidae) for herbaceous seeds. Acta Zool Acad Sci Hung 65:57-76

Sirami C et al (2019) Increasing crop heterogeneity enhances multitrophic diversity across agricultural regions. Proc Natl Acad Sci USA 116:16442-16447

Trichard A, Alignier A, Biju-Duval L, Petit S (2013) The relative effects of local management and landscape context on weed seed predation and carabid functional groups. Basic Appl Ecol 14:235-245

Tschumi M, Ekroos J, Hjort C, Smith HG, Birkhofer K (2018) Predation-mediated ecosystem services and disservices in agricultural landscapes. Ecol Appl 28:2109-2118

Venables WN, Ripley BD (2002) Modern applied statistics with S, 4th edn. Springer, New York

Westerman P, Liebman M, Menalled FD, Heggenstaller AH, Hartzler RG, Dixon PM (2005) Are many little hammers effective?-Velvetleaf (Abutilon theophrasti) population dynamics in two- and four-year crop rotation systems. Weed Sci 53:382-392

Winqvist C et al (2014) Species' traits influence ground beetle responses to farm and landscape level agricultural intensification in Europe. J Insect Conserv 18:837-846

Publisher's Note Springer Nature remains neutral with regard to jurisdictional claims in published maps and institutional affiliations. 